\title{
Analysis of order review/release problems in production systems
}

\author{
I. Sabuncuoglu*, H.Y. Karapınar \\ Department of Industrial Engineering, Bilkent University, 06533 Ankara, Turkey
}

Received 4 May 1998; accepted 17 November 1998

\begin{abstract}
Order Review/Release (ORR) activities have mostly been ignored in past job shop research. In most previous studies, arriving jobs are immediately released to the shop floor without considering any information about the system or job characteristics. In practice however, these jobs are often first collected in a pool and then released to the system according to a specific criterion. Although practitioners often observe the benefits of ORR, researchers have found limited support for the use of these input reglation policies. One objective of this paper is to examine this research paradox in a capacitated system. We also offer a new classification framework for existing research work. Finally, for the first time in this paper, both periodic and continuous ORR methods are compared simultaneously under various experimental conditions against different performance measures. The results of simulation experiments and statistical tests are also presented in the paper. (C) 1999 Elsevier Science B.V. All rights reserved.
\end{abstract}

Keywords: Order review/release; Input control; Scheduling; Job shop; Simulation

\section{Introduction}

It is known in practice that controlling input rate has a great impact on the system performance. In manufacturing systems, this input regulation is performed by the Order Review/Release (ORR) function which is also referred to as input sequencing [1], input/output control [2], controlled release [3], input control [4] and input regulation [5].

The purpose of ORR is to improve system performance by controlling the flow of production orders to the system (i.e., the timing and conditions of order release decisions). These improvements can

\footnotetext{
* Corresponding author. Tel.: 90312 2901607; fax: 90312266 4126; e-mail: sabun@bilkent.edu.tr.
}

be achieved in terms of increased flexibility, decreased work in process, improved delivery performance, reduced congestion and manufacturing lead times [6]. The existing applications have also showed that ORR, if implemented properly, can simplify other shop floor activities (e.g., dispatching) due to controlling the number of jobs in the system. As indicated by Ragatz and Mabert [7], it is also an effective capacity management tool.

The timing of release decisions is important because early releases cause congestion on the shop floor, possibility of damage and obsolescence, higher inventory holding costs, occupation of valuable factory space, and interference with urgent jobs. On the other hand, late releases can result in missed due-dates, loss of goodwill, idle resources, and increased lead times. Since the consequences of 
sub-optimal ORR decisions can be very severe, ORR systems should be designed carefully and implemented effectively.

Despite the fact that ORR performs such an important function, it has been mostly ignored in past job shop research. In most studies, arriving jobs are immediately released to the shop floor without considering any information about the system and the job characteristics. In practice, however, these jobs are often first collected in a pool and then released to the system according to some criterion [8-11]. One practical reason for not releasing the jobs immediately is the fact that major production/inventory decisions in practice are made periodically (i.e., daily, weekly, etc). Another reason is that holding an order until a last moment before being released ensures that output can be better matched with actual demand [8]. Moreover, the system performance is less affected by revisions of a upper level of planning system (i.e., master production schedule) and/or changes in customer orders or specifications [4]. Consequently, the jobs are released to the shop floor in a controlled manner in practice (usually on the periodic basis).

The literature on ORR is relatively recent. Most of the significant research in this area has been done after the mid-eighties. A number of ORR methods have been proposed since then. These methods have been compared for various performance measures under different operating conditions. The results of these simulation-based studies have demonstrated some of the benefits of ORR mechanisms. However, as indicated by Melnyk et al. [12], ORR systems also presents a research paradox, because researchers have found limited support for the use of ORR for some performance measures in their simulation studies. Specifically, overall lead times (or total time in system) could not be reduced by ORR even though some shop performance measures such as work in process, queue time, and some due-date and cost performances were improved. Furthermore, as has been observed in some cases $[4,13]$, the most effective strategy to optimize due-date related performance measures such as mean tardiness is to release the jobs to the system immediately. However, this is completely contrary to what is expected from ORR. One of the purposes of this paper is to shed light on this paradox. We believe that the potential benefits of ORR can be realized in research environments if congestion is properly modeled. For that reason, we decided to reexamine the problem using a system in which congestion is explicitly modeled. Specifically, we consider the job shop with materials handling system and finite buffer capacities, and show how a load-based release method can improve overall manufacturing lead times. At this point, we should also point out the fact that the full benefit from ORR can realized without an affective capacity planning system being present. In this respect, ORR should be viewed as a capacity management tool which performs finer capacity adjustments prior to a dispatching function. In this paper, we assume that all the major capacity planning related issues are resolved and our focus is on the effective material flow and release of orders on the shop floor.

In this paper, we also propose a new classification framework by which the existing studies in the literature can be easily classified. To our knowledge, this is the most comprehensive and up to date review of ORR. Moreover, we compare some well known ORR methods under various experimental conditions for different performance measures. Indeed, our study is the first detailed simulation study in which both periodic and continuous ORR methods are compared simultaneously.

The rest of the paper is organized as follows. In Section 2, a classification framework is presented and the ORR literature is reviewed. This is followed by a description of the simulation model, system considerations, and experimental design in Section 3. The research paradox is examined in Section 4. Comparisons of ORR methods and statistical tests on the simulation results are given in Section 5. Finally, concluding remarks are made and future research direction are outlined in Section 6.

\section{Literature review}

In recent years, there has been a growing interest in ORR research. As a result, a number of ORR methods have been proposed in the literature. Simulation-based studies have been performed to investigate several issues concerning with the ORR 
problems and solution approaches. The objectives of this section is to summarize the major findings of previous work and identify potential research areas.

Our classification is basically an extension of that of Philipoom et al. [14] who identified two major categories of ORR methods: load-limited release and release methods based on calculated release times. In this paper, we consider some additional factors and propose the following classification scheme:

1. ORR Mechanisms which do not use any information about shop status or characteristics of the jobs to be released. The methods in this category can be further classified into:

(a) Immediate Release (IMR): This mechanism releases jobs to the shop immediately. Hence, the release time of an order is equal to its arrival time. Most job shop research which ignores the ORR function, uses this mechanism. It may also be considered as the "no order review/release" case, and is often used in the literature as a benchmark in comparisons. Although it is a naive rule, most simulation studies have found that it is superior to other ORR methods under some conditions.

(b) Interval Release (IR): This mechanism can be considered as a periodic version of IMR. Jobs are first collected in a release pool and then released to the shop periodically. This policy may represent a situation where the jobs are held in the pool for paperwork (or other purposes) and released in batches periodically (i.e., at the beginning of a shift or day).

2. Load limited order release: Jobs are released to the shop according to the current workload in the shop. No due-date information is utilized. The methods in this category can be further classified into:

(a) Aggregate Loading (AGG): Release decisions are based on an aggregate measure such as total workload (i.e., amount of work in hours) or total number of jobs on the shop floor. In this respect, $\mathrm{AGG}$ can be considered as a valve (or gate) that restricts the existing shop load to a specified limit.

(b) Workcenter Information Based Loading (WIBL): It utilizes more detailed information than AGG. Specifically, total workloads of the jobs on their process routings are considered to make the release decision. A periodic version of this release mechanism is called the Path-Based Bottleneck (PBB) method [14].

3. Release mechanisms based on calculated release times: The basic idea is to release the jobs at predetermined release times based on flow time estimates. These methods utilize information on long-term capacity utilization and job due-dates to provide on-time deliveries. They can also be classified into:

(a) Infinite Loading (INF): As shown below, the release time is calculated by subtracting the expected flow time from due-date of a job:

$R_{i}=D_{i}-F_{i}$

where

$R_{i}=$ release time of job $i$,

$D_{i}=$ due date of job $i$,

$F_{i}=$ flow time estimate of job $i$.

Readers can refer to Mahmoodi et al. [13], Ragatz and Mabert [7] and Philipoom et al. [14] for alternative ways of setting flow time allowances in the ORR context. Shop capacity information is not explicitly considered by INF.

(b) Finite Loading (FIN): The methods in this category uses more detailed information about the jobs and the system. Essentially, FIN considers available shop capacity over the planning horizon and tries to match machine requirements of the jobs with the available capacity [6]. Two types of FIN can be identified:

i. Forward Finite Loading (FFIN): This approach loads all operations of the job into available capacity starting from the first operation. The release decision of a particular job is based on the loading period of the last operation and the due-date of a job. The job is released if the loading period of the last operation is within a preset time window about the due-date.

ii. Backward Finite Loading (BFIN): This method operates in the opposite direction. That is, each operation is placed into available capacity starting with the last 
operation of the job and working backward from the job's due-date. As compared to FFIN, the release decision is based on the loading period of first operation and the current time. The job is released if this period is within a preset time window from the current time.

As discussed in [15] there are two versions of the finite loading: vertical loading and horizontal loading. In the former case, machines are loaded one by one. It is similar to the way machines are scheduled one at a time by dispatching rules in a dynamic job shop environment. In the latter case, all operations of a job are loaded before the next job is considered. The second approach has been used in most ORR research.

4. Release mechanisms that consider both the workload level in the shop and the due dates of the jobs: These mechanisms attempt to control the workload level in the shop and to provide on-time deliveries. They are basically extensions of load limited release with additional considerations on due dates.
A list of the existing studies based on our classification scheme is given in Table 1. As can be noted, there are a number of ORR methods and several studies to compare them. Results of these studies indicate that effective use of ORR policies has positive effects on system performance. Specifically, they reduce work in process and variability on the shop floor. In a recent study by Melnyk et al. [33], it has been shown that the system performance is significantly influenced by the release time distribution and its parameters. In addition, the task of dispatching (or scheduling) can be made easier under the presence of ORR due to fewer items on the shop floor. Other findings can be summarized as follows:

1. Due-date based release mechanisms seem to improve the due-date performance of non-duedate based dispatching rules (i.e., the rules such as SPT and FCFS which do not use any duedate information) more than the due-date based rules.

2. Due-date oriented release methods (e.g., FIN, INF) performs very well for the mean lateness and the mean absolute deviation measures.

Table 1

Classification of the literature

1. Group One:

- IMR: Melnyk and Ragatz [16]; Panwalkar et al. [17]; Mahmoodi et al. [13]; Philipoom et al. [14]; Hendry and Wong [18]; Kim and Bobrowski [19]

- IR: Panwalkar et al. [17]; Mahmoodi et al. [13]; Melnyk et al. [12]; Melnyk et al. [9]; Bobrowski and Park [6]; Ahmed and Fisher [20]; Ragatz and Mabert [7]; Hansmann [21]

2. Group Two:

- AGG: Melnyk and Ragatz [16]; Melnyk et al. [12]; Melnyk et al. [9]; Bobrowski and Park [6]; Ragatz and Mabert [7]; Hendry and Wong [18]; Kim and Bobrowski [19]; Roderick et al. [22]; Glassey and Resende [23]; Baker [4]; Spearman et al. [24];

- WIBL: Hendry and Kingsman [25]; Hendry and Wong [18]; Irastorza and Deane [26]; Melnyk and Ragatz [16]; Philipoom et al. [14]; Goldratt and Fox [27]

3. Group Three:

- INF: Mahmoodi et al. [13]; Philipoom et al. [14]; Bobrowski and Park [6]; Park and Bobrowski [28]; Ahmed and Fisher [20]; Ragatz and Mabert [7]; Roderick et al. [22]

- FIN:

FFIN: Bobrowski [29]; Bobrowski and Park [6]; Park and Bobrowski [28]; Ahmed and Fisher [20] Lingayat et al. [30]; Kim and Bobrowski [19] BFIN: Ragatz and Mabert [7]; Kim and Bobrowski [19]

4. Group Four: Hansmann [21]; Wiendahl et al. [31]; Baker [4]; Bechte [32]; Bechte [10]; Onur and Fabrycky [2]; Ashby and Uzsoy [11] 
3. Load oriented release methods such as AGG and WIBL outperform due-date oriented release methods for the mean tardiness and the proportion tardy measures.

4. For the cost based measures, INF seems to be better than other rules.

5. Combinations of ORR and load smoothing (i.e., adjusting loads over the periods) reduces lead times and work in process on the shop floor [9]. As indicated by Melnyk et al. [12], the effectiveness of ORR can be greatly enhanced by controlling variance in the system.

6. There are significant interactions between the ORR policies and due-date assignment methods. The best rule combinations seem to depend on the system conditions and dispatching rules in use [20].

7. The recent study by Malhotra et al. [34] pointed out a need for further research in ORR for multiple customer priority classes.

8. The best policy for reducing the mean flow time (i.e., time in the pool plus time in the shop), the mean tardiness and the proportion tardiness is to release the jobs immediately. As described earlier, this situation is controversial issue which will be investigated in this paper.

9. Except for Panwalkar et al. [17] there is no study where continuous and periodic ORR mechanisms are compared. The relative performance of other methods are not generally known. In this paper, we will also provide this comparison.

10. Finally, as indicated by Ashby and Uzsoy [11], the benefits of ORR and its interactions with dispatching differ considerably depending on the nature of the system, production process and product mix. In this context, the type of the system studied in this paper (i.e., job shop with material handling and finite buffer capacities) will form a different production environment for the ORR policies to be tested.

\section{Experimental conditions}

\subsection{System considerations and simulation model}

The job shop model is developed using the SIMAN simulation package [35]. The program runs in UNIX environment. Some of the characteristics of the job shop model are identical to the one used by Melnyk and Ragatz [16]. Additionally, a material handling system and finite buffer capacities are added to the model to simulate congestion on the shop floor. These new features are included to study the research paradox stated earlier in the paper. The system consists of six departments (workcenters). We assume that there is one machine in each department. Order (or job) arrival is according to Poisson process. The routing is purely random with the number of operations uniformly distributed between 1 and 6 . When an order arrives, its due-date is assigned using the total work content (TWK) rule which is the most commonly used rule in the literature. According to this rule, due-dates are assigned in proportion to total processing times. Processing times are generated from the Erlang distribution with parameter 1 unit time.

Material flow is bi-directional and parts are transferred between machines by free path transporters (i.e., forklifts). Distances between the work centers are given in Table 2. There are five transporters operating at a speed of 250 distance units per hour. Two types of dispatching decisions are made to operate the material handling system: (a) selecting a transporter from a set of idle transporters to assign for a request, and (b) selecting a work center from a set of work centers requesting a transporter. The first is called workstation initiated task assignment and the second is known as vehicle initiated task assignment [36]. For workstation initiated task assignment, we used Smallest

Table 2

Vehicle travel distances between workcenters (in distance units)

\begin{tabular}{llrrrrrrr}
\hline $\begin{array}{l}\text { Station } \\
\text { No. }\end{array}$ & 2 & 3 & 4 & 5 & 6 & 7 & 8 \\
\hline 1 & 0 & 80 & 85 & 75 & 130 & 95 & 40 & 125 \\
2 & & 0 & 35 & 95 & 80 & 145 & 70 & 135 \\
3 & & & 0 & 60 & 45 & 110 & 105 & 100 \\
4 & & & & 0 & 55 & 50 & 115 & 80 \\
5 & & & & & 0 & 85 & 150 & 55 \\
6 & & & & & & 0 & 135 & 30 \\
7 & & & & & & & 0 & 165 \\
8 & & & & & & & & \\
\hline
\end{tabular}


Distance to Station (SDS) rule, where the transporter nearest to the station making the request is allocated. For vehicle initiated task assignment, we use modified-first-come-first-served (MOD FCFS) rule.

Machines have finite input/output buffer capacities, capable of holding four jobs. There is also another buffer area in each department with a relatively large buffer capacity, representing a common departmental storage area. The finite buffer capacity and material handling makes our simulation model different from the other models in the ORR literature. Because the structure of the system modeled is different from others in the literature, we made some extensions to the operational rules as described below. A transporter request is always made whenever a job is released to the shop from the pool or whenever job is put in the output queue. When a transporter arrives at its destination, it unloads the job if there is an empty place in the input queue and there is no job waiting at the departmental buffer. Otherwise, it takes it to the departmental storage area. We assumed that the distance between the machine and this common buffer area is 25 distance units for each department. After unloading the job to the input queue, the transporter picks up the oldest unassigned load at the output queue. If there is no unassigned load at the output queue, the transporter is directed to the station from where the oldest transporter request has been made. If there is no transporter request in the system, the transporter remains idle at this station. If there is no space in the output queue when an operation is completed, the job waits on the machine until a job at the output queue is removed. Hence, the machine is blocked. Finally, if the number of jobs in the input queue drops below a threshold value (currently equal to one) and there are jobs waiting in the departmental buffer area, a transporter request is made by the station to fill the respective input queue.

\subsection{Experimental factors}

In the simulation experiments, four major factors are considered. These are ORR mechanism, dispatching rule, system load level (both machining subsystem and material handling system), and due-date tightness.

As seen in Table 3, four continuous and five periodic ORR mechanisms are tested in the experiments. These methods are selected from each group in Table 1 according to their performance in previous studies. For each release mechanism, first in first out (FIFO) is used to rank the jobs in the release pool. To dispatch the jobs on the shop floor, two rules are used. The first rule is SPT (Shortest Processing Time) which approximately minimizes the mean flow time and work in process. As a duedate oriented rule, MOD (Modified Operation Due-date) is used in the experiments, because this rule is known as a very effective rule for tardiness related measures [37].

Most of the ORR mechanisms listed in Table 3 have one or more parameters to be specified. There are even different versions of these methods which are frequently reported in the literature. In Table 4, we list the current values of these parameters and the reference(s) from which these versions are taken. For example, PINF is taken from Ragatz and

Table 3

Experimental factors and their levels

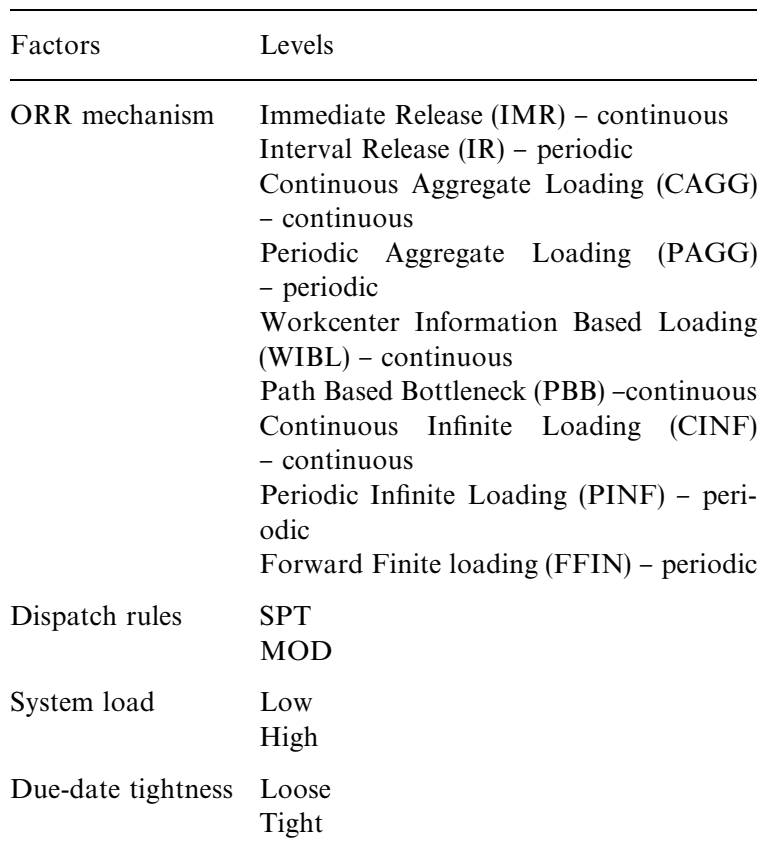


Table 4

ORR methods and their parameters, and sources of references

\begin{tabular}{|c|c|c|}
\hline Methods & Parameters & References \\
\hline IMR & None & {$[13]$} \\
\hline IR & Period length $=8 \mathrm{~h}$ & {$[17]$} \\
\hline CAGG & Load allowed $=$ found empirically & {$[38]$} \\
\hline PAGG & $\begin{array}{l}\text { Period length }=8 \mathrm{~h} \text { and } \\
\text { load allowed }=\text { found empirically }\end{array}$ & [7] \\
\hline WIBL & Load allowed $=$ found empirically & {$[16]$} \\
\hline PBB & Load level = found empirically & {$[14]$} \\
\hline CINF & $R_{i}=D_{i}-k_{1} n_{i}-k_{2} Q_{i}$ & $\begin{array}{l}\text { used in this } \\
\text { study only }\end{array}$ \\
\hline & $k_{1}$ and $k_{2}$ are determined empirically & \\
\hline PINF & $\begin{array}{l}\text { Period length }=8 \mathrm{~h} \text { and } \\
R_{i}=D_{i}-k_{1} n_{i}-k_{2} Q_{i}\end{array}$ & {$[7]$} \\
\hline FFIN & $\begin{array}{l}\text { Period length }=8 \mathrm{~h} \text { and } k \text { value } \\
\text { of Flow time }=k \text { Processing time }\end{array}$ & {$[6]$} \\
\hline
\end{tabular}

Mabert [7] and its regression coefficients are estimated in our study.

The system load level is adjusted by changing the arrival rate. At the high level, machine and transporter utilization rates are approximately $91 \%$ and $93 \%$, respectively. This is achieved by setting the mean time between arrival to $0.705 \mathrm{~h}$. At the low level, it is set to $0.9 \mathrm{~h}$ which resulted in $66 \%$ and $63 \%$ utilizations, respectively.

Two levels of due-date tightness are considered. As shown in Table 5, the tightness level is controlled by the parameter $k$ of the TWK rule. Due-dates are assigned such that the percent of tardy jobs are $10 \%$ and $30 \%$ for the loose and tight cases, respectively. These values are set in pilot experiments by using FIFO dispatching rule.

In this study, the method of batch means is used for simulation output data analysis [39]. In this method, a very long simulation run is broken down into smaller subruns (or batches). Our pilot runs indicated that the warm-up period and approximately independent batch sizes are equal to 2500 and 1000 job completions. Since each simulation run consists of twenty batches, we have a total run length of 22500 jobs. These simulation runs are repeated for each factor combination to implement the full factorial design. Since there are nine ORR methods and two levels of the other factors (i.e., scheduling method, due-date tightness, and system
Table 5

Tightness parameter of TWK for experimental conditions

\begin{tabular}{lll}
\hline $\begin{array}{l}\text { Machine and } \\
\text { transporter utilization }\end{array}$ & $\begin{array}{l}\text { Due-date } \\
\text { tightness level }\end{array}$ & $\begin{array}{l}\text { Parameter } k^{\mathrm{a}} \\
\text { of the TWK rule }\end{array}$ \\
\hline Low & Loose & 6.5 \\
Low & Tight & 4.1 \\
High & Loose & 33.0 \\
High & Tight & 15.0
\end{tabular}

${ }^{\mathrm{a}} D_{i}=\mathrm{AT}_{i}+k \mathrm{TWK}_{i}$, where $D_{i}=$ due-date of job $i, \mathrm{AT}_{i}=$ arrival time of job $i, \mathrm{TWK}_{i}=$ total operation time of job $i, k=$ tightness parameter.

load level), 72 factor combinations are tested in the experiments.

Common random numbers (CRN) are used to provide the same experimental condition across the runs for each factor combination. Because we manipulate random variability, a randomized complete block design is used for the statistical analyses.

We present the results of the simulation experiments for the following performance measures:

Flow time $\quad=$ time in pool + time in shop,

Time in system $=$ time in pool + time in shop + time in finished goods inventory,

Tardiness $\quad=\max \left(0, C_{i}-D_{i}\right)$,

Lateness $\quad=C_{i}-D_{i}$,

Absolute deviation $=\left|C_{i}-D_{i}\right|$,

where $C_{i}$ and $D_{i}$ are the completion time and due date of job $i$, respectively. Time in finished good inventory is the waiting time of an early completed job until it is withdrawn at its due date. In addition to the above measures, statistics such as percent tardy, time in input queue, time in output queue, and blocking time, are also collected to provide additional insights into the performances of the ORR methods.

\section{Analysis of research paradox}

This section is devoted to the analysis of the research paradox stated earlier in the paper. To study this problem, we measure the performance of 
different job shop configurations using the continuous aggregate loading mechanism (CAGG). Our conjecture is that the potential benefits of ORR, which are frequently observed in practice, can also be realized in research settings as long as congestion is properly modeled. To prove this conjecture, we analyze the following jobs shop configurations:

1. Case 1: a system which does not have any material handling system and capacitated queues (i.e., traditional job shop).

2. Case 2: a system in which there is a material handling system, but not capacitated queues.

3. Case 3: a system which considers capacitated queues, but not a material handling system.

4. Case 4: a system which considers both capacitated queues and a material handling system.
As can be noted, these job shop models are listed in the order of the increased system details. In the experiments, SPT is used as the dispatching rule and the system load (or utilization) is set to the high level (i.e., 90\%) for loose due-dates. Since the primary measure is the mean flow time, the results are also presented for the major components of the mean flow time such as time in pool and time in queue (Table 6). Immediate release (IMR) is also included in the analysis to provide a benchmark for comparisons. Fig. 1 displays the mean flow time performance of the first three systems at varying values of number of jobs allowed into the system, which is the parameter of CAGG.

In general, the results indicate that limiting the number of jobs released to the system increases the mean flow time values for each of the three job shop configurations tested. As also observed by other

Table 6

Simulation results of Aggregate Loading(cont.) with SPT dispatching rule at high system utilization with loose due dates for the three cases

\begin{tabular}{|c|c|c|c|c|c|c|c|}
\hline Number of jobs allowed & & 18 & 20 & 25 & 30 & 40 & 60 \\
\hline \multirow[t]{3}{*}{ Mean flow time } & $\mathrm{C} 1$ & 10.47 & 10.15 & 9.83 & 9.78 & 9.79 & 9.79 \\
\hline & $\mathrm{C} 2$ & 18.43 & 16.61 & 13.60 & 13.29 & 13.13 & 13.16 \\
\hline & $\mathrm{C} 3$ & 12.82 & 11.87 & 11.08 & 11.00 & 10.97 & 10.93 \\
\hline \multirow[t]{3}{*}{ Time in system } & $\mathrm{C} 1$ & 115.30 & 115.30 & 115.30 & 115.30 & 115.30 & 115.30 \\
\hline & $\mathrm{C} 2$ & 116.90 & 115.40 & 115.30 & 115.30 & 115.30 & 115.30 \\
\hline & $\mathrm{C} 3$ & 115.40 & 115.30 & 115.30 & 115.30 & 115.30 & 115.30 \\
\hline \multirow[t]{3}{*}{ Time in shop } & $\mathrm{C} 1$ & 9.35 & 9.52 & 9.71 & 9.77 & 9.79 & 9.79 \\
\hline & $\mathrm{C} 2$ & 11.32 & 11.72 & 12.25 & 12.48 & 12.50 & 12.54 \\
\hline & $\mathrm{C} 3$ & 10.08 & 10.32 & 10.65 & 10.83 & 10.96 & 10.93 \\
\hline \multirow[t]{3}{*}{ Time in pool } & $\mathrm{C} 1$ & 1.12 & 0.63 & 0.11 & 0.01 & 0.00 & 0.00 \\
\hline & $\mathrm{C} 2$ & 17.11 & 4.88 & 1.35 & 0.80 & 0.63 & 0.62 \\
\hline & $\mathrm{C} 3$ & 2.73 & 1.54 & 0.42 & 0.16 & 0.01 & 0.00 \\
\hline \multirow[t]{3}{*}{ Time in input queue } & $\mathrm{C} 1$ & 5.85 & 6.02 & 6.22 & 6.27 & 6.29 & 6.29 \\
\hline & $\mathrm{C} 2$ & 5.12 & 5.48 & 5.96 & 6.19 & 6.21 & 6.23 \\
\hline & $\mathrm{C} 3$ & 4.94 & 5.00 & 5.05 & 5.08 & 5.10 & 5.09 \\
\hline \multirow[t]{3}{*}{ Time in output queue } & $\mathrm{C} 1$ & 0.00 & 0.00 & 0.00 & 0.00 & 0.00 & 0.00 \\
\hline & $\mathrm{C} 2$ & 1.13 & 1.17 & 1.21 & 1.22 & 1.22 & 1.23 \\
\hline & $\mathrm{C} 3$ & 1.64 & 1.82 & 2.10 & 2.25 & 2.36 & 2.34 \\
\hline \multirow[t]{3}{*}{ Time in finished good inv. } & $\mathrm{C} 1$ & 104.90 & 105.20 & 105.50 & 105.50 & 105.50 & 105.50 \\
\hline & $\mathrm{C} 2$ & 88.50 & 98.80 & 101.70 & 102.00 & 102.20 & 102.20 \\
\hline & $\mathrm{C} 3$ & 102.60 & 103.50 & 104.20 & 104.30 & 104.30 & 104.40 \\
\hline \multirow[t]{3}{*}{$M / H$ time } & $\mathrm{C} 1$ & 0.00 & 0.00 & 0.00 & 0.00 & 0.00 & 0.00 \\
\hline & $\mathrm{C} 2$ & 1.57 & 1.57 & 1.57 & 1.57 & 1.57 & 1.57 \\
\hline & $\mathrm{C} 3$ & 0.00 & 0.00 & 0.00 & 0.00 & 0.00 & 0.00 \\
\hline
\end{tabular}




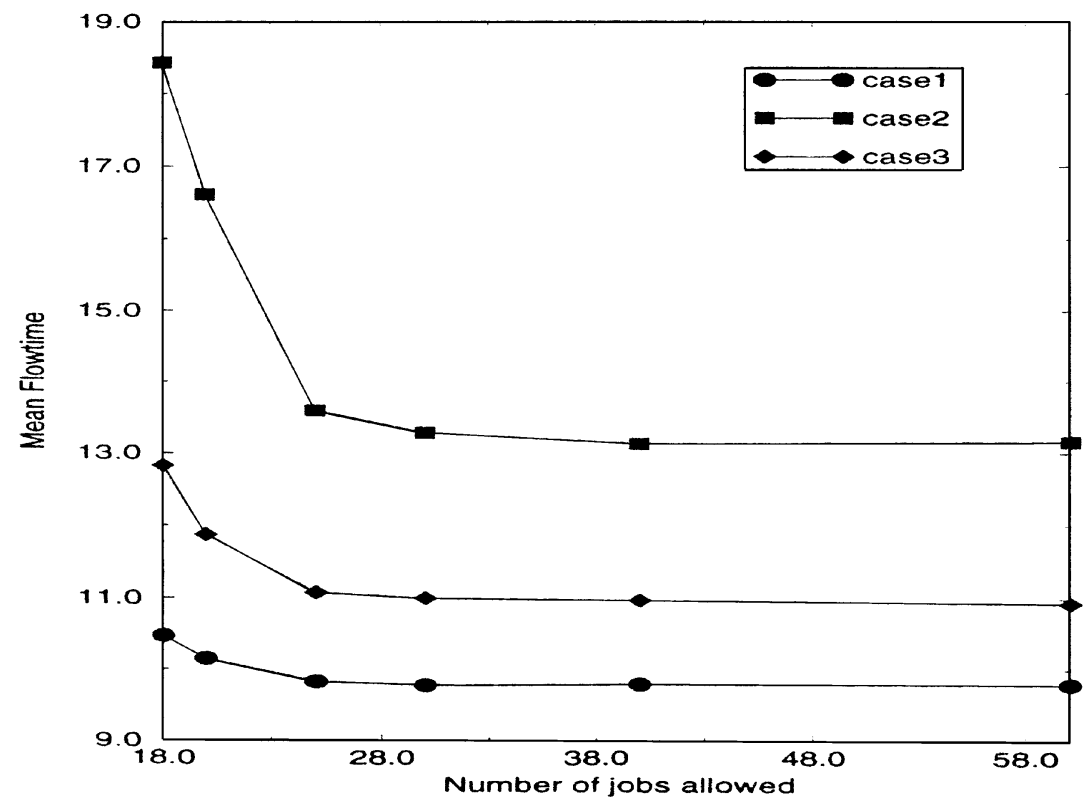

Fig. 1. Mean flow time versus number of jobs allowed for the three cases (aggregate loading with SPT dispatching rule at high system utilization with loose due-dates).

researchers [16] this is due to the fact that ORR shifts a part of total queue time from the shop to the release pool.

Moreover, at low parameter values of CAGG, the increase in pool time is more than possible reductions in queue time that the total time in system (i.e., flow time) increases in the controlled release. This finding confirms the previous results reported in the literature that limiting job releases can cause the possibility of starvation of machines, losing valuable production capacity. Consideration of material handling and finite buffer capacities adversely affect system performance as the curves for Cases 2 and 3 shift upward. The adverse effect of MHS on system performance seems to be greater than that of the capacitated queues. In conclusion, the use of ORR (or CAGG in our case) does not improve overall system performance even though it reduces WIP on the shop floor. Next, we consider Case 4 in which both finite queue capacities and a material handling system are considered simultaneously.

In contrast to three cases discussed previously, the controlled release improves the mean flow time.
In fact, U-shaped behavior is observed at this time (see Fig. 2). This phonemenon can be better explained by examining the components of the flow time.

At the lower parameter values of CAGG where the system is underloaded, jobs spent a considerable amount of time in the release pool instead of being processed in the system. At higher parameter values where the system is overloaded, material handling time increases because the transporters often visit the departmental buffer areas. As a result, time in output queue increases since the transporters become busy most of the time when there are more jobs on the shop floor. Consequently, when there are either too few or too many jobs on the shop floor, the mean flow-time increases drastically and its general behavior resembles a $\mathrm{U}$ convex curve.

This is an important finding because it explains at least in our case why and how ORR can improve the overall time in system (or mean flowtime) by controlling the input rate, that was not previously reported in the ORR literature. Note that the absence U-shaped behavior in Cases 1-3 highlights 

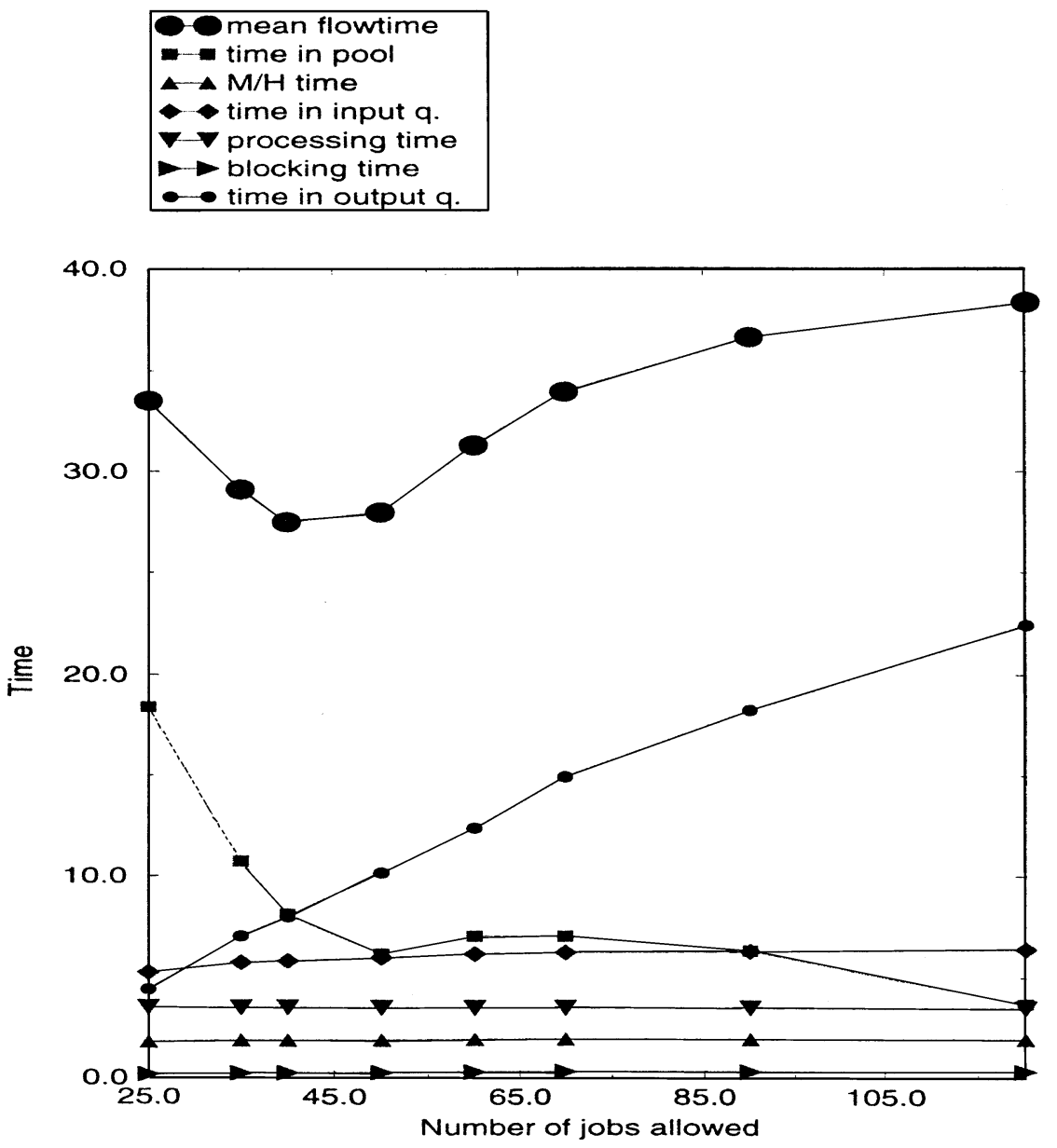

Fig. 2. Components of the flow time (for CAGG) with SPT dispatching rule at high system utilization and loose due-dates.

the importance of MHS and finite buffer capacities for modeling congestion on the shop floor.

We also measured the sensitivity of previous results (i.e., U-shaped behavior) to different experimental conditions. When simulation experiments are repeated at low machine and MHS utilization rates, we note that limiting the number of jobs released to the shop does not improve the mean flow time. In other words, the positive impact of the ORR is not realizable when the system utilization is low. It seems that ORR is only beneficial when the system is highly loaded (i.e., congested shop floor conditions). Having identified conditions under which ORR is effective, we looked at the mean tardiness performance measures and observed the same behavior (U-type curve).

We also checked whether this behavior is prevalent for different dispatching rules and release methods. As seen in the sample figures (Figs. 3 and 4), simulation results confirmed our expectations (note that the conditions that are different from the base case (conditions of Fig. 3) are highlighted in the labels of these figures). Hence, we conclude that the system performance is improved by ORR as long as the models include all the necessary system details and important factors.

At this point, we should also remind the reader that the system modeled in this study is a very 


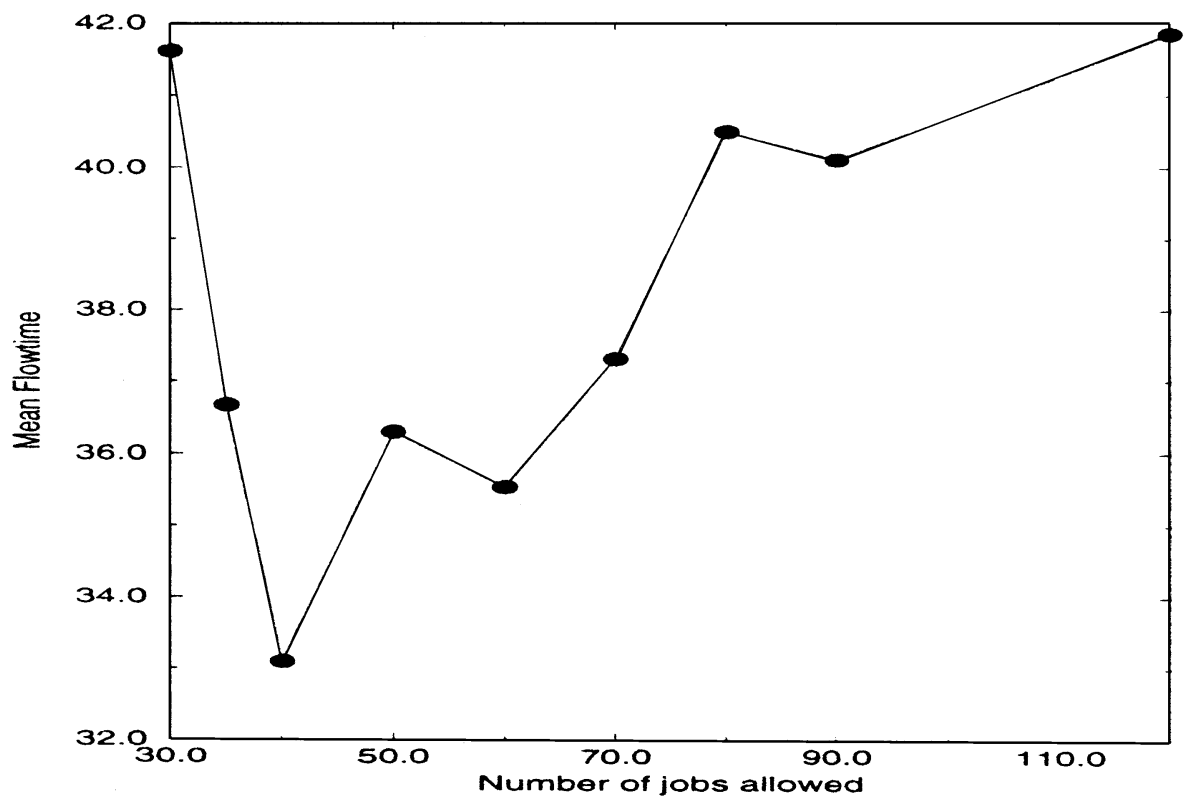

Fig. 3. Mean flow time versus number of jobs allowed (for CAGG) with MOD dispatching rule under low system utilization with loose due-dates.

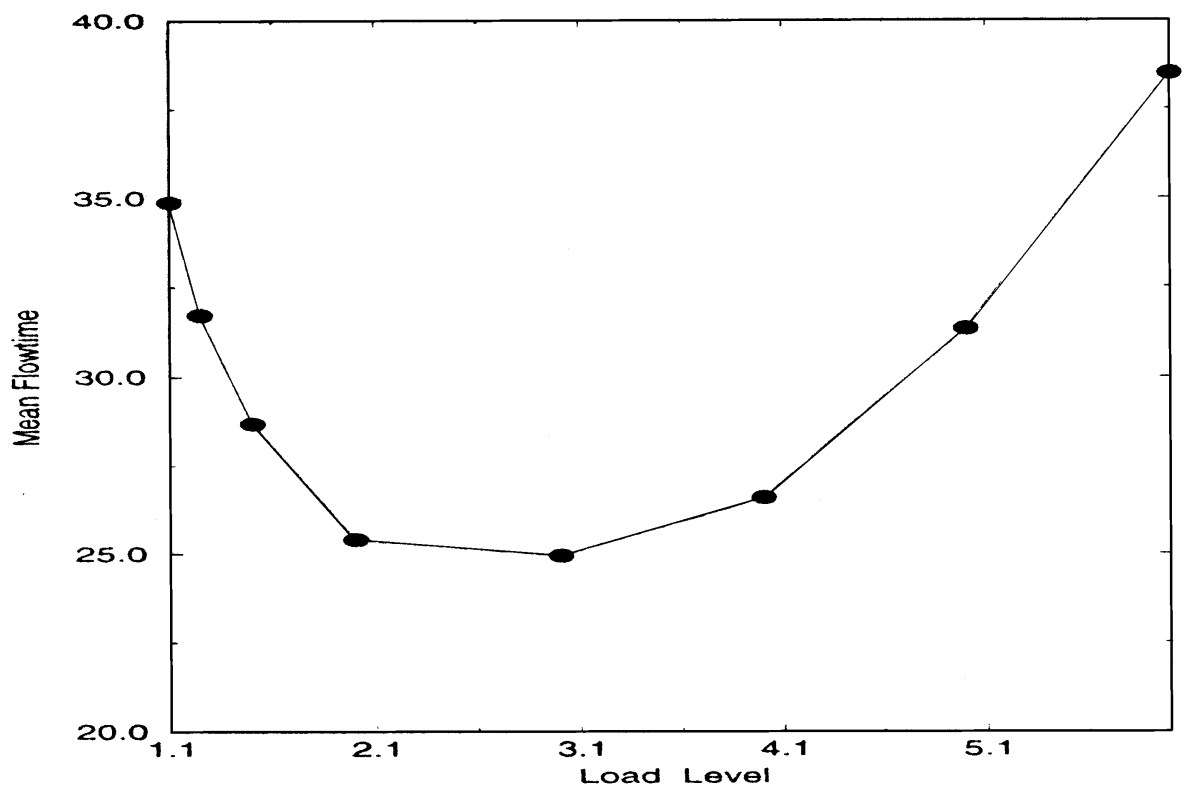

Fig. 4. Mean flow time versus load level (for WIBL with SPT dispatching rule at high system utilization with loose due-dates).

specific system with finite buffer capacities and materials handling subsystem (i.e., an extension of classical job shop model). There may be other ways to incorporate the negative effects of congestion in the models. This could be, for example, modeling confusion on the shop floor due to long job queues, difficulty in expediting and dispatching, possibility of damage and rework due to extra handling, or 
wasting resource times due to changes in customer orders and part requirements, etc. All these and many other real-life features can be included in the research models to show how ORR improves overall manufacturing lead times and due-date performance of the systems.

\section{Comparisons of ORR methods}

In this section, we compare nine ORR mechanisms under various experimental conditions using the system given in Case 4. Simulation results are presented for different performance measures such as mean flow time, mean tardiness, and mean absolute deviation. As discussed earlier, there are eight experimental points resulting from the combination of two dispatching rules (SPT and MOD), two system load levels (high and low) and two due date tightness levels (tight and loose). Twenty simulation runs are taken at each experimental point using the batch means method.

Except the IMR rule, most of the ORR methods considered in this study have one or more parameters to be specified. Hence, additional simulation runs are made to find their best values experimentally. For example, the simulation model is run for each performance measure at varying values of the number of jobs allowed parameter of CAGG, PAGG and PPB and those with the best performances are selected for further comparisons. Similarly, we tested different load levels of the WIBL method and used the best performer during comparisons.

For some other rules such as CINF, PINF and FFIN, there are parameters to be estimated by regression analysis. To accomplish this we conducted simulation experiments at each design point. The data sets were collected based on 1200 observations which includes actual flow times, job characteristics and the shop status information. Then linear regression models were fit to these data sets. Finally, we used an 8-hour duration as the period length for all the periodic ORR methods.

Tables 7 and 8 show the overall mean performances of the methods at each condition (as can be noted in Table 7, the row "loose, high and CAGG" is underlined to indicate that it corresponds to the base case in the research paradox section). The results are also analyzed by ANOVA for statistical significance, considering all factor combinations. Finally, Multiple Comparison Procedures (MCP) are used to rank the ORR methods for each performance measure.

In general, the results indicated that continuous rules (e.g., IMR and CAGG) produce better mean flow time and tardiness performance than their periodic counterparts (e.g., IR and PAGG). This is due to the fact that the release decisions are postponed in the periodic case, which in turn creates an extra waiting (or idle) time for some jobs in the release pool that eventually increases overall flow times.

We also observed that the relative performances of the ORR methods depends on experimental conditions (i.e., load level, tightness factor) and dispatching rules as well as the performance measures in use. The details of the results and formal statistical tests are given next.

\subsection{Further analysis of results}

The analysis of variance (ANOVA) for each performance measure is given in Table 9. Bonferroni method is also used to rank the ORR methods at each experimental condition (Table 10).

\subsubsection{Mean flow time}

The ANOVA indicates that main effects of all the factors other than dispatching rules tested in this study are significant. The reason for not finding the dispatching factor significant can be attributed to the type of the system studied in this paper. Recall that our system is a capacitated system with limited input and output queue spaces at each machine. In such a system, since the half of these buffer spaces are occupied by outgoing parts, dispatching rules may not have opportunity to show different performance within the remaining number of incoming parts. Moreover, ORR mechanisms in use may have reduced the effect of dispatching on the system performance by limiting the number of jobs on the shop floor [4].

According to the Bonferroni test, the relative ordering of the ORR methods is affected by conditions. 
Table 7

Simulation results for SPT dispatching rule

\begin{tabular}{|c|c|c|c|c|c|c|c|c|c|}
\hline \multirow{2}{*}{$\begin{array}{l}\text { Due date } \\
\text { tightness }\end{array}$} & \multirow{2}{*}{$\begin{array}{l}\text { Load } \\
\text { level }\end{array}$} & \multirow{2}{*}{$\begin{array}{l}\text { ORR } \\
\text { rule }\end{array}$} & \multicolumn{7}{|c|}{ Performance measures } \\
\hline & & & MF & MT & PT & ML & MAD & $\mathrm{NJ}$ & $\mathrm{SF}$ \\
\hline \multirow{9}{*}{ Loose } & \multirow{9}{*}{ Low } & CAGG & 9.9 & 0.09 & 5.2 & -10.5 & 12.0 & 10.2 & 5.9 \\
\hline & & CINF & 23.1 & 1.7 & 47.0 & 0.4 & 3.1 & 11.5 & 15.7 \\
\hline & & FFIN & 24.1 & 3.3 & 58.8 & 1.4 & 5.2 & 14.7 & 13.0 \\
\hline & & IMR & 9.9 & 0.08 & 5.2 & -12.8 & 13.0 & 10.9 & 6.0 \\
\hline & & IR & 16.5 & 1.3 & 31.4 & -6.2 & 8.9 & 13.2 & 7.2 \\
\hline & & PAGG & 16.5 & 1.3 & 31.2 & -3.8 & 8.9 & 12.3 & 7.1 \\
\hline & & PBB & 16.5 & 1.3 & 31.2 & -1.6 & 8.7 & 11.3 & 7.2 \\
\hline & & PINF & 24.4 & 3.1 & 58.3 & 1.6 & 4.5 & 14.3 & 14.4 \\
\hline & & WIBL & 9.9 & 0.09 & 5.2 & -10.0 & 12.2 & 9.6 & 6.0 \\
\hline \multirow{9}{*}{ Loose } & \multirow{9}{*}{ High } & CAGG & 27.4 & 0.5 & 3.7 & -77.0 & 81.8 & 22.1 & 12.7 \\
\hline & & $\overline{\mathrm{CINF}}$ & $\overline{179.6}$ & $\overline{79.9}$ & $\overline{53.9}$ & $\overline{64.1}$ & 95.7 & $\overline{219.1}$ & $\overline{173.0}$ \\
\hline & & FFIN & 174.6 & 67.6 & 57.8 & 59.1 & 76.0 & 169.3 & 145.9 \\
\hline & & IMR & 44.5 & 6.0 & 8.9 & -70.8 & 82.8 & 62.9 & 40.2 \\
\hline & & IR & 73.0 & 13.1 & 17.8 & -42.2 & 68.4 & 96.1 & 61.9 \\
\hline & & PAGG & 60.2 & 5.5 & 17.7 & -46.6 & 63.1 & 39.4 & 20.4 \\
\hline & & PBB & 61.9 & 4.8 & 17.1 & -43.2 & 59.0 & 23.6 & 29.8 \\
\hline & & PINF & 220.7 & 121.7 & 55.1 & 105.4 & 137.9 & 294.2 & 220.7 \\
\hline & & WIBL & 24.9 & 1.2 & 5.2 & -76.8 & 88.1 & 16.5 & 18.2 \\
\hline \multirow{9}{*}{ Tight } & \multirow{9}{*}{ Low } & CAGG & 9.8 & 0.41 & 19.4 & -2.1 & 5.2 & 10.2 & 5.9 \\
\hline & & CINF & 15.2 & 1.9 & 55.0 & 0.9 & 2.9 & 11.6 & 10.5 \\
\hline & & FFIN & 17.4 & 4.2 & 71.7 & 3.0 & 5.3 & 13.5 & 7.9 \\
\hline & & IMR & 9.8 & 0.4 & 19.4 & -4.4 & 5.2 & 10.9 & 6.0 \\
\hline & & IR & 16.4 & 3.7 & 66.9 & 2.1 & 5.3 & 13.1 & 7.1 \\
\hline & & PAGG & 16.4 & 3.7 & 66.7 & 2.1 & 5.3 & 12.3 & 7.1 \\
\hline & & PBB & 16.4 & 3.7 & 66.5 & 2.1 & 5.3 & 11.3 & 7.1 \\
\hline & & PINF & 18.2 & 4.5 & 76.3 & 3.9 & 5.2 & 13.6 & 9.0 \\
\hline & & WIBL & 9.8 & 0.4 & 19.4 & -1.7 & 5.2 & 9.6 & 6.0 \\
\hline \multirow{9}{*}{ Tight } & \multirow{9}{*}{ High } & CAGG & 27.7 & 3.2 & 16.9 & -17.0 & 85.7 & 22.2 & 12.5 \\
\hline & & CINF & 100.0 & 52.1 & 61.8 & 47.6 & 56.7 & 128.3 & 94.5 \\
\hline & & FFIN & 80.3 & 37.5 & 52.2 & 27.9 & 47.0 & 103.9 & 71.5 \\
\hline & & IMR & 40.2 & 12.7 & 20.0 & -12.2 & 37.6 & 56.8 & 36.1 \\
\hline & & IR & 78.7 & 36.5 & 52.4 & 26.2 & 46.7 & 104.0 & 69.3 \\
\hline & & PAGG & 61.2 & 20.5 & 50.4 & 8.8 & 32.2 & 39.1 & 19.9 \\
\hline & & PBB & 60.3 & 18.9 & 50.4 & 7.9 & 29.9 & 23.5 & 28.6 \\
\hline & & PINF & 118.9 & 68.9 & 77.4 & 66.6 & 71.3 & 156.8 & 114.3 \\
\hline & & WIBL & 25.3 & 3.9 & 15.5 & -12.1 & 34.7 & 16.5 & 18.7 \\
\hline
\end{tabular}

Note: MF: Mean Flow time, MT: Mean Tardiness, PT: Percent Tardy, ML: Mean Lateness, MAD: Mean Absolute Deviation, NJ: Average Number of Jobs in the Shop, SF: Standard Deviation of Flow time.

In general, two continuous rules, WIBL and CAGG, are the best for the mean flow time criterion when the system load is high. But when the load is low, IMR is as competitive as these two rules. Among the periodic rules, PBB, PAGG and IR displayed better performances than PINF and
FFIN. The ORR methods which utilize current system load information (i.e., PAGG, CAGG, WIBL, and PBB) improve the mean flow time more than FFIN.

The results also indicated that increasing the load level and using loose due dates adversely 
Table 8

Simulation results for MOD dispatching rule

\begin{tabular}{|c|c|c|c|c|c|c|c|c|c|}
\hline \multirow{2}{*}{$\begin{array}{l}\text { Due date } \\
\text { tightness }\end{array}$} & \multirow{2}{*}{$\begin{array}{l}\text { Load } \\
\text { level }\end{array}$} & \multirow{2}{*}{$\begin{array}{l}\text { ORR } \\
\text { rule }\end{array}$} & \multicolumn{7}{|c|}{ Performance measures } \\
\hline & & & MF & MT & PT & ML & MAD & $\mathrm{NJ}$ & $\mathrm{SF}$ \\
\hline \multirow{9}{*}{ Loose } & \multirow{9}{*}{ Low } & CAGG & 10.5 & 0.07 & 5.1 & -8.9 & 11.0 & 10.6 & 6.7 \\
\hline & & $\mathrm{CINF}$ & 23.2 & 1.6 & 52.3 & 0.4 & 2.7 & 12.2 & 15.2 \\
\hline & & FFIN & 23.7 & 3.1 & 57.6 & 0.9 & 5.1 & 14.6 & 12.6 \\
\hline & & IMR & 10.5 & 0.07 & 5.1 & -12.1 & 12.3 & 11.6 & 6.8 \\
\hline & & IR & 16.5 & 1.3 & 31.4 & -6.1 & 8.8 & 13.3 & 7.3 \\
\hline & & PAGG & 16.6 & 1.3 & 31.2 & -3.9 & 8.7 & 12.3 & 7.2 \\
\hline & & PBB & 16.5 & 1.3 & 31.0 & -1.8 & 8.5 & 11.3 & 7.3 \\
\hline & & PINF & 24.3 & 3.1 & 59.1 & 1.6 & 4.5 & 14.4 & 14.2 \\
\hline & & WIBL & 10.5 & 0.07 & 5.1 & -9.7 & 11.8 & 9.9 & 6.6 \\
\hline \multirow{9}{*}{ Loose } & \multirow{9}{*}{ High } & CAGG & 33.0 & 0.6 & 4.2 & -55.5 & 71.2 & 24.1 & 16.2 \\
\hline & & CINF & 172.5 & 60.2 & 78.1 & 56.9 & 63.5 & 207.5 & 135.2 \\
\hline & & FFIN & 164.6 & 54.7 & 72.1 & 49.2 & 60.2 & 166.5 & 126.7 \\
\hline & & IMR & 44.1 & 1.7 & 8.1 & -71.2 & 74.6 & 62.6 & 34.6 \\
\hline & & IR & 70.6 & 4.8 & 21.3 & -44.7 & 54.3 & 92.8 & 48.2 \\
\hline & & PAGG & 59.8 & 3.0 & 15.1 & -45.3 & 56.1 & 40.0 & 23.2 \\
\hline & & PBB & 59.8 & 3.3 & 16.4 & -42.4 & 53.0 & 24.0 & 29.0 \\
\hline & & PINF & 198.3 & 85.2 & 87.1 & 83.0 & 87.5 & 259.9 & 170.6 \\
\hline & & WIBL & 27.4 & 1.6 & 6.0 & -63.4 & 83.7 & 17.9 & 19.8 \\
\hline \multirow{9}{*}{ Tight } & \multirow{9}{*}{ Low } & CAGG & 10.3 & 0.3 & 20.1 & -1.1 & 4.7 & 10.4 & 6.3 \\
\hline & & CINF & 15.1 & 1.6 & 58.1 & 0.7 & 2.4 & 11.8 & 9.9 \\
\hline & & FFIN & 17.3 & 4.1 & 71.5 & 2.9 & 5.3 & 13.5 & 7.7 \\
\hline & & IMR & 10.3 & 0.3 & 20.2 & -3.9 & 4.7 & 11.4 & 6.4 \\
\hline & & IR & 16.4 & 3.7 & 67.2 & 2.1 & 5.3 & 13.1 & 7.1 \\
\hline & & PAGG & 16.4 & 3.7 & 67.2 & 2.1 & 5.3 & 12.3 & 7.1 \\
\hline & & PBB & 16.4 & 3.7 & 67.3 & 2.1 & 5.3 & 11.3 & 7.1 \\
\hline & & PINF & 17.9 & 4.4 & 74.7 & 3.6 & 5.1 & 13.5 & 8.8 \\
\hline & & WIBL & 10.3 & 0.3 & 20.2 & -1.3 & 4.7 & 9.9 & 6.4 \\
\hline \multirow{9}{*}{ Tight } & \multirow{9}{*}{ High } & CAGG & 32.0 & 3.2 & 18.6 & -3.1 & 25.9 & 23.7 & 15.2 \\
\hline & & CINF & 97.6 & 46.5 & 82.1 & 45.2 & 47.8 & 124.3 & 82.5 \\
\hline & & FFIN & 68.7 & 26.7 & 54.8 & 16.3 & 37.1 & 90.0 & 53.5 \\
\hline & & IMR & 47.5 & 14.8 & 29.6 & -4.9 & 34.6 & 67.2 & 39.4 \\
\hline & & IR & 74.2 & 31.0 & 58.3 & 21.8 & 40.2 & 97.8 & 59.4 \\
\hline & & PAGG & 59.8 & 17.2 & 51.6 & 6.0 & 28.4 & 38.7 & 20.1 \\
\hline & & PBB & 58.3 & 17.5 & 50.8 & 5.8 & 29.2 & 23.7 & 27.9 \\
\hline & & PINF & 111.3 & 59.5 & 92.3 & 58.9 & 60.1 & 145.8 & 93.3 \\
\hline & & WIBL & 26.5 & 1.6 & 16.4 & -5.4 & 33.2 & 17.8 & 18.5 \\
\hline
\end{tabular}

Note: MF: Mean Flow time, MT: Mean Tardiness, PT: Percent Tardy, ML: Mean Lateness, MAD: Mean Absolute Deviation, NJ: Average Number of Jobs in the Shop, SF: Standard Deviation of Flow time.

affects the mean flow time performance. This is probably because of the increased congestion on the shop floor at high load levels. We also observed that, when the due dates are loose, the ORR mechanisms such as CINF, PINF and FFIN hold more jobs in the release pool, which eventually increases the system flow times.

Finally, an analysis of two way interactions indicated that the relative performances of the ORR methods are affected significantly by due date 
Table 9

Anova results for three performance measures

\begin{tabular}{|c|c|c|c|c|c|}
\hline Source & $\mathrm{DF}$ & Sum of squares & F value & Pr gt F & Significant at $0.05 ?$ \\
\hline \multicolumn{6}{|c|}{ Mean Flow Time } \\
\hline Model & 90 & 3905720.61 & 101.90 & 0.0001 & Yes \\
\hline Error & 1349 & 574533.78 & & & \\
\hline $\mathrm{B}$ & 19 & 379282.38 & 46.87 & 0.0001 & Yes \\
\hline $\mathrm{U}$ & 1 & 1472891.99 & 3458.34 & 0.0001 & Yes \\
\hline $\mathrm{T}$ & 1 & 90603.90 & 212.74 & 0.0001 & Yes \\
\hline $\mathrm{D}$ & 1 & 707.91 & 1.66 & 0.1975 & No \\
\hline $\mathrm{R}$ & 8 & 909242.18 & 266.86 & 0.0001 & Yes \\
\hline $\mathrm{U} * \mathrm{~T}$ & 1 & 65315.35 & 153.36 & 0.0001 & Yes \\
\hline $\mathrm{U} * \mathrm{D}$ & 1 & 864.26 & 2.03 & 0.1545 & No \\
\hline $\mathrm{U} * \mathrm{R}$ & 8 & 652817.03 & 191.60 & 0.0001 & Yes \\
\hline $\mathrm{T} * \mathrm{D}$ & 1 & 104.66 & 0.25 & 0.6202 & No \\
\hline $\mathrm{T} * \mathrm{R}$ & 8 & 186833.33 & 54.84 & 0.0001 & Yes \\
\hline $\mathrm{D} * \mathrm{R}$ & 8 & 3728.66 & 1.09 & 0.3642 & No \\
\hline $\mathrm{U} * \mathrm{~T} * \mathrm{D}$ & 1 & 120.97 & 0.28 & 0.5942 & No \\
\hline $\mathrm{U} * \mathrm{~T} * \mathrm{R}$ & 8 & 138706.61 & 40.71 & 0.0001 & Yes \\
\hline $\mathrm{U} * \mathrm{D} * \mathrm{R}$ & 8 & 3133.54 & 0.92 & 0.4990 & No \\
\hline $\mathrm{T} * \mathrm{D} * \mathrm{R}$ & 8 & 668.64 & 0.20 & 0.9914 & No \\
\hline $\mathrm{U} * \mathrm{~T} * \mathrm{D} * \mathrm{R}$ & 8 & 699.12 & 0.21 & 0.9900 & No \\
\hline \multicolumn{6}{|c|}{ Mean Tardiness } \\
\hline Model & 90 & 1062088.65 & 36.17 & 0.0001 & Yes \\
\hline Error & 1349 & 440141.33 & & & \\
\hline $\mathrm{B}$ & 19 & 181052.14 & 29.21 & 0.0001 & Yes \\
\hline $\mathrm{U}$ & 1 & 234602.83 & 719.04 & 0.0001 & Yes \\
\hline $\mathrm{T}$ & 1 & 134.51 & 0.41 & 0.5209 & No \\
\hline $\mathrm{D}$ & 1 & 4168.94 & 12.78 & 0.0004 & Yes \\
\hline $\mathrm{R}$ & 8 & 290338.71 & 111.23 & 0.0001 & Yes \\
\hline $\mathrm{U} * \mathrm{~T}$ & 1 & 1140.19 & 3.49 & 0.0618 & No \\
\hline $\mathrm{U} * \mathrm{D}$ & 1 & 3991.07 & 12.23 & 0.0005 & Yes \\
\hline $\mathrm{U} * \mathrm{R}$ & 8 & 254071.18 & 97.34 & 0.0001 & Yes \\
\hline $\mathrm{T} * \mathrm{D}$ & 1 & 660.12 & 2.02 & 0.1551 & No \\
\hline $\mathrm{T} * \mathrm{R}$ & 8 & 40471.52 & 15.51 & 0.0001 & Yes \\
\hline $\mathrm{D} * \mathrm{R}$ & 8 & 4827.69 & 1.85 & 0.0642 & No \\
\hline $\mathrm{U} * \mathrm{~T} * \mathrm{D}$ & 1 & 666.53 & 2.04 & 0.1532 & No \\
\hline $\mathrm{U} * \mathrm{~T} * \mathrm{R}$ & 8 & 37632.65 & 14.42 & 0.0001 & Yes \\
\hline $\mathrm{U} * \mathrm{D} * \mathrm{R}$ & 8 & 4703.69 & 1.80 & 0.0726 & No \\
\hline $\mathrm{T} * \mathrm{D} * \mathrm{R}$ & 8 & 1791.14 & 0.69 & 0.7041 & No \\
\hline $\mathrm{U} * \mathrm{~T} * \mathrm{D} * \mathrm{R}$ & 8 & 1835.67 & 0.70 & 0.6889 & No \\
\hline \multicolumn{6}{|c|}{ Mean Absolute Deviation } \\
\hline Model & 90 & 1478329.38 & 39.91 & 0.0001 & Yes \\
\hline Error & 1349 & 555203.17 & & & \\
\hline $\mathrm{B}$ & 19 & 55218.11 & 7.06 & 0.0001 & Yes \\
\hline $\mathrm{U}$ & 1 & 1002336.60 & 2435.42 & 0.0001 & Yes \\
\hline $\mathrm{T}$ & 1 & 114495.35 & 278.19 & 0.0001 & Yes \\
\hline $\mathrm{D}$ & 1 & 18839.79 & 45.78 & 0.0001 & Yes \\
\hline $\mathrm{R}$ & 8 & 55811.73 & 16.95 & 0.0001 & Yes \\
\hline $\mathrm{U} * \mathrm{~T}$ & 1 & 74484.66 & 180.98 & 0.0001 & Yes \\
\hline $\mathrm{U} * \mathrm{D}$ & 1 & 17344.58 & 42.14 & 0.0001 & Yes \\
\hline $\mathrm{U} * \mathrm{R}$ & 8 & 68668.84 & 20.86 & 0.0001 & Yes \\
\hline
\end{tabular}


Table 9. Continued.

\begin{tabular}{llcccc}
\hline Source & DF & Sum of squares & F value & Pr gt F & Significant at 0.05? \\
\hline $\mathrm{T} * \mathrm{D}$ & 1 & 567.66 & 1.38 & 0.2404 & No \\
$\mathrm{T} * \mathrm{R}$ & 8 & 13387.50 & 4.07 & 0.0001 & Yes \\
$\mathrm{D} * \mathrm{R}$ & 8 & 11693.34 & 3.55 & 0.0004 & Yes \\
$\mathrm{U} * \mathrm{~T} * \mathrm{D}$ & 1 & 543.95 & 1.32 & 0.2505 & Yes \\
$\mathrm{U} * \mathrm{~T} * \mathrm{R}$ & 8 & 11231.43 & 3.41 & 0.0007 & Yes \\
$\mathrm{U} * \mathrm{D} * \mathrm{R}$ & 8 & 11438.24 & 3.47 & 0.0006 & Yes \\
$\mathrm{T} * \mathrm{D} * \mathrm{R}$ & 8 & 11024.16 & 3.35 & 0.0008 & Yes \\
$\mathrm{U} * \mathrm{~T} * \mathrm{D} * \mathrm{R}$ & 8 & 11243.36 & 3.41 & 0.0007 & \\
\hline
\end{tabular}

U: Utilization, T: Due date tightness, D: Dispatching rule, R: Release mechanism.

Table 10

Bonferroni's multiple range test results

\begin{tabular}{|c|c|c|c|c|c|c|c|}
\hline \multirow[t]{2}{*}{ Due-date } & \multirow[t]{2}{*}{ Load level } & \multicolumn{3}{|l|}{ SPT } & \multicolumn{3}{|l|}{ MOD } \\
\hline & & Ranking & Mean & ORR & Ranking & Mean & ORR \\
\hline \multirow{4}{*}{\multicolumn{2}{|c|}{ Mean Flow Time }} & A & 24.39 & PINF & A & 24.36 & PINF \\
\hline & & A & 24.16 & FFIN & $\mathrm{B}$ & 23.72 & FFIN \\
\hline & & B & 23.15 & CINF & $\mathrm{C}$ & 23.23 & CINF \\
\hline & & $\mathrm{C}$ & 16.55 & PBB & $\mathrm{D}$ & 16.63 & PAGG \\
\hline \multirow[t]{8}{*}{ Loose } & \multirow[t]{8}{*}{ Low } & $\mathrm{C}$ & 16.51 & IR & $\mathrm{D}$ & 16.59 & IR \\
\hline & & $\mathrm{C}$ & 16.51 & PAGG & $\mathrm{D}$ & 16.57 & PBB \\
\hline & & $\mathrm{D}$ & 9.92 & WIBL & $\mathrm{C}$ & 16.57 & CAGG \\
\hline & & $\mathrm{D}$ & 9.91 & IMR & $\mathrm{C}$ & 16.55 & IMR \\
\hline & & $\mathrm{D}$ & 9.91 & CAGG & $\mathrm{C}$ & 16.53 & WIBL \\
\hline & & A & 220.76 & PINF & A & 198.35 & PINF \\
\hline & & $\mathrm{B}$ & 179.60 & CINF & $\mathrm{B}$ & 172.51 & CINF \\
\hline & & $\mathrm{B}$ & 174.60 & FFIN & B & 164.61 & FFIN \\
\hline \multirow[t]{10}{*}{ Loose } & \multirow[t]{10}{*}{ High } & $\mathrm{C}$ & 73.05 & IR & $\mathrm{C}$ & 70.65 & IR \\
\hline & & $\mathrm{CD}$ & 61.90 & PBB & $\mathrm{CD}$ & 59.87 & PAGG \\
\hline & & $\mathrm{CD}$ & 60.20 & PAGG & $\mathrm{DC}$ & 59.84 & PBB \\
\hline & & $\mathrm{CD}$ & 44.50 & IMR & $\mathrm{DE}$ & 44.14 & IMR \\
\hline & & $\mathrm{E}$ & 27.46 & CAGG & $\mathrm{D}$ & 33.09 & CAGG \\
\hline & & $\mathrm{E}$ & 24.94 & WIBL & $\mathrm{E}$ & 7.42 & WIBL \\
\hline & & A & 18.23 & PINF & A & 17.99 & PINF \\
\hline & & B & 17.42 & FFIN & B & 17.31 & FFIN \\
\hline & & $\mathrm{C}$ & 16.45 & IR & $\mathrm{C}$ & 16.46 & PAGG \\
\hline & & $\mathrm{C}$ & 16.43 & PBB & $\mathrm{C}$ & 16.44 & IR \\
\hline \multirow[t]{10}{*}{ Tight } & \multirow[t]{10}{*}{ Low } & $\mathrm{C}$ & 16.43 & PAGG & $\mathrm{C}$ & 16.43 & PBB \\
\hline & & $\mathrm{D}$ & 15.26 & CINF & $\mathrm{D}$ & 15.13 & CINF \\
\hline & & $\mathrm{E}$ & 9.98 & WIBL & $\mathrm{E}$ & 10.36 & WIBL \\
\hline & & $\mathrm{F}$ & 9.87 & IMR & $\mathrm{E}$ & 10.35 & IR \\
\hline & & $\mathrm{F}$ & 9.87 & CAGG & $\mathrm{E}$ & 10.35 & CAGG \\
\hline & & A & 118.98 & PINF & A & 111.37 & PINF \\
\hline & & $\mathrm{B}$ & 100.09 & CINF & A & 97.65 & CINF \\
\hline & & $\mathrm{C}$ & 80.30 & FFIN & B & 74.25 & IR \\
\hline & & $\mathrm{C}$ & 78.70 & IR & $\mathrm{CB}$ & 68.80 & FFIN \\
\hline & & $\mathrm{D}$ & 61.27 & PAGG & CBD & 59.84 & PBB \\
\hline
\end{tabular}


Table 10. Continued.

\begin{tabular}{|c|c|c|c|c|c|c|c|}
\hline \multirow[t]{2}{*}{ Due-date } & \multirow[t]{2}{*}{ Load level } & \multicolumn{3}{|l|}{ SPT } & \multicolumn{3}{|l|}{ MOD } \\
\hline & & Ranking & Mean & ORR & Ranking & Mean & ORR \\
\hline \multirow[t]{4}{*}{ Tight } & \multirow[t]{4}{*}{ High } & $\mathrm{D}$ & 60.36 & PBB & $\mathrm{CD}$ & 58.52 & PAGG \\
\hline & & $\mathrm{E}$ & 40.23 & IMR & ED & 47.52 & IMR \\
\hline & & $\mathrm{E}$ & 27.72 & CAGG & ED & 32.08 & CAGG \\
\hline & & $\mathrm{E}$ & 25.36 & WIBL & $\mathrm{F}$ & 26.53 & WIBL \\
\hline \multicolumn{8}{|c|}{ Mean Tardiness } \\
\hline & & A & 3.34 & FFIN & A & 3.09 & FFIN \\
\hline & & $\mathrm{B}$ & 3.09 & PINF & A & 3.06 & PINF \\
\hline & & $\mathrm{C}$ & 1.77 & CINF & $\mathrm{B}$ & 1.60 & CINF \\
\hline & & $\mathrm{D}$ & 1.37 & IR & $\mathrm{C}$ & 1.34 & PAGG \\
\hline \multirow[t]{8}{*}{ Loose } & \multirow[t]{8}{*}{ Low } & $\mathrm{D}$ & 1.36 & PBB & $\mathrm{C}$ & 1.33 & IR \\
\hline & & $\mathrm{D}$ & 1.36 & PAGG & $\mathrm{C}$ & 1.32 & PBB \\
\hline & & $\mathrm{E}$ & 0.09 & WIBL & $\mathrm{D}$ & 0.07 & WIBL \\
\hline & & $\mathrm{E}$ & 0.09 & CAGG & $\mathrm{D}$ & 0.07 & IMR \\
\hline & & $\mathrm{E}$ & 0.08 & IMR & $\mathrm{D}$ & 0.07 & CAGG \\
\hline & & $\mathrm{A}$ & 121.70 & PINF & $\mathrm{A}$ & 85.28 & PINF \\
\hline & & $\mathrm{B}$ & 79.96 & CINF & B & 60.26 & CINF \\
\hline & & B & 67.60 & FFIN & B & 54.74 & FFIN \\
\hline \multirow{10}{*}{ Loose } & \multirow{10}{*}{ High } & $\mathrm{C}$ & 13.10 & IR & $\mathrm{C}$ & 4.81 & IR \\
\hline & & $\mathrm{C}$ & 6.08 & IMR & $\mathrm{C}$ & 3.38 & PBB \\
\hline & & $\mathrm{C}$ & 5.59 & PAGG & $\mathrm{C}$ & 3.06 & PAGG \\
\hline & & $\mathrm{C}$ & 4.83 & PPB & $\mathrm{C}$ & 1.71 & IMR \\
\hline & & $\mathrm{C}$ & 1.26 & WIBL & $\mathrm{C}$ & 1.59 & WIBL \\
\hline & & $\mathrm{C}$ & 0.50 & CAGG & $\mathrm{C}$ & 0.66 & CAGG \\
\hline & & $\mathrm{A}$ & 4.56 & PINF & A & 4.40 & PINF \\
\hline & & $\mathrm{B}$ & 4.23 & FFIN & A & 4.16 & FFIN \\
\hline & & $\mathrm{C}$ & 3.73 & IR & A & 3.73 & PAGG \\
\hline & & $\mathrm{C}$ & 3.73 & PAGG & B & 3.71 & PBB \\
\hline \multirow[t]{9}{*}{ Tight } & \multirow[t]{9}{*}{ Low } & $\mathrm{C}$ & 3.72 & PBB & B & 3.71 & IR \\
\hline & & $\mathrm{D}$ & 1.92 & CINF & $\mathrm{C}$ & 1.61 & CINF \\
\hline & & $\mathrm{E}$ & 0.41 & IMR & $\mathrm{D}$ & 0.38 & IMR \\
\hline & & $\mathrm{E}$ & 0.41 & CAGG & $\mathrm{D}$ & 0.37 & $\mathrm{CAGG}$ \\
\hline & & $\mathrm{E}$ & 0.41 & WIBL & $\mathrm{D}$ & 0.37 & WIBL \\
\hline & & A & 68.95 & PINF & A & 59.57 & PINF \\
\hline & & BA & 52.18 & CINF & BA & 46.54 & CINF \\
\hline & & $\mathrm{BC}$ & 37.50 & FFIN & $\mathrm{BC}$ & 31.09 & IR \\
\hline & & $\mathrm{BCD}$ & 36.5 & IR & $\mathrm{BC}$ & 26.76 & FFIN \\
\hline \multirow[t]{5}{*}{ Tight } & \multirow[t]{5}{*}{ High } & CDE & 20.54 & PAGG & $\mathrm{BC}$ & 17.55 & PBB \\
\hline & & $\mathrm{DE}$ & 18.94 & PPB & $\mathrm{DC}$ & 17.27 & PAGG \\
\hline & & $\mathrm{E}$ & 12.72 & IMR & $\mathrm{DC}$ & 14.87 & IMR \\
\hline & & $\mathrm{E}$ & 3.98 & WIBL & $\mathrm{D}$ & 3.25 & $\mathrm{CAGG}$ \\
\hline & & $\mathrm{E}$ & 3.26 & CAGG & $\mathrm{D}$ & 1.59 & WIBL \\
\hline \multicolumn{8}{|c|}{ Mean Absolute Deviation } \\
\hline & & A & 13.00 & IMR & A & 12.32 & IMR \\
\hline & & $\mathrm{B}$ & 12.19 & WIBL & B & 11.83 & WIBL \\
\hline & & B & 12.00 & CAGG & $\mathrm{C}$ & 11.09 & $\mathrm{CAGG}$ \\
\hline & & $\mathrm{C}$ & 8.96 & IR & $\mathrm{D}$ & 8.81 & IR \\
\hline
\end{tabular}


Table 10. Continued.

\begin{tabular}{|c|c|c|c|c|c|c|c|}
\hline \multirow[t]{2}{*}{ Due-date } & \multirow[t]{2}{*}{ Load level } & \multicolumn{3}{|l|}{ SPT } & \multicolumn{3}{|l|}{ MOD } \\
\hline & & Ranking & Mean & ORR & Ranking & Mean & ORR \\
\hline \multirow[t]{8}{*}{ Loose } & \multirow[t]{8}{*}{ Low } & $\mathrm{C}$ & 8.96 & PAGG & $\mathrm{D}$ & 8.77 & PAGG \\
\hline & & $\mathrm{C}$ & 8.67 & PBB & $\mathrm{D}$ & 8.57 & PBB \\
\hline & & D & 5.25 & FINF & $\mathrm{E}$ & 5.19 & FFIN \\
\hline & & $\mathrm{E}$ & 4.49 & PINF & $\mathrm{F}$ & 4.50 & PINF \\
\hline & & $\mathrm{F}$ & 3.13 & CINF & G & 2.70 & CINF \\
\hline & & A & 137.99 & PINF & A & 87.56 & PINF \\
\hline & & B & 95.77 & CINF & BA & 83.78 & WIBL \\
\hline & & $\mathrm{BC}$ & 88.13 & WIBL & $\mathrm{BA}$ & 74.63 & IMR \\
\hline \multirow[t]{10}{*}{ Loose } & \multirow[t]{10}{*}{ High } & $\mathrm{BC}$ & 82.90 & IMR & $\mathrm{BA}$ & 71.28 & CAGG \\
\hline & & $\mathrm{BC}$ & 81.89 & CAGG & BA & 63.54 & CINF \\
\hline & & $\mathrm{BC}$ & 76.04 & FFIN & BA & 60.27 & FFIN \\
\hline & & $\mathrm{CB}$ & 68.49 & IR & BA & 56.19 & PAGG \\
\hline & & $\mathrm{CB}$ & 64.31 & PAGG & B & 54.35 & IR \\
\hline & & $\mathrm{C}$ & 59.08 & PBB & B & 53.05 & PBB \\
\hline & & A & 5.38 & FFIN & A & 5.34 & FFIN \\
\hline & & A & 5.35 & PAGG & A & 5.31 & PBB \\
\hline & & A & 5.35 & IR & A & 5.31 & PAGG \\
\hline & & A & 5.32 & PBB & A & 5.30 & IR \\
\hline \multirow[t]{8}{*}{ Tight } & \multirow[t]{8}{*}{ Low } & A & 5.28 & IMR & A & 5.15 & PINF \\
\hline & & A & 5.28 & CAGG & $\mathrm{AB}$ & 4.72 & CAGG \\
\hline & & A & 5.28 & WIBL & B & 4.72 & IMR \\
\hline & & B & 5.22 & PINF & B & 4.71 & WIBL \\
\hline & & $\mathrm{C}$ & 2.91 & CINF & $\mathrm{C}$ & 2.42 & CINF \\
\hline & & A & 85.67 & CAGG & A & 60.18 & PINF \\
\hline & & BA & 71.31 & PINF & BA & 47.86 & CINF \\
\hline & & $\mathrm{BC}$ & 56.71 & CINF & $\mathrm{BC}$ & 40.23 & IR \\
\hline \multirow[t]{6}{*}{ Tight } & \multirow[t]{6}{*}{ High } & DC & 46.75 & FFIN & $\mathrm{BC}$ & 37.17 & FFIN \\
\hline & & DC & 44.74 & IR & $\mathrm{BC}$ & 34.67 & IMR \\
\hline & & $\mathrm{C}$ & 37.68 & IMR & $\mathrm{BC}$ & 33.28 & WIBL \\
\hline & & $\mathrm{D}$ & 34.77 & WIBL & $\mathrm{C}$ & 29.20 & PBB \\
\hline & & D & 32.28 & PAGG & $\mathrm{C}$ & 28.47 & PAGG \\
\hline & & $\mathrm{D}$ & 29.98 & PBB & $\mathrm{C}$ & 25.97 & CAGG \\
\hline
\end{tabular}

tightness and system load level. In general, differences between ORR methods become more significant as the load and tightness levels increase. This is also verified by repeating the MCPs in the high utilization and tight due date cases; MCP find the differences between the methods easily when the system is highly loaded or due-dates are very tight.

\subsubsection{Mean tardiness}

In the mean tardiness case, except for the duedate tightness factor, the effects of all the main factors were significant. The reasons for not finding the tightness significant further investigated. Our analysis showed that methods such as CINF, PINF and FFIN finish operations of the jobs around their due dates. For that reason, most jobs become tardy regardless of the due-date tightness levels. This behavior is more apparent at the high system utilization levels. At this point, it was suggested that the tightness factor can be made significant if the above three ORR methods are excluded from the analysis. Hence, we repeated the ANOVA tests excluding these two ORR methods. The results of these tests confirmed our expectations. An analysis 
of two way interactions indicated that both the release methods and dispatch rules are considerably affected by the system load level and due-date tightness. In general, difference between the methods become more significant as the tightness and system load level increase.

As compared to the mean flow time case, the dispatching rule factor was significant in favor of the MOD rule at this time. The relative ranking of the ORR methods change from one condition to another. But in general, CAGG, WIBL, and IMR are better ORR policies which are followed by two periodic rules, $\mathrm{PBB}$ and PAGG. These two methods perform better than FFIN, CINF, and PINF in the experiments.

\subsubsection{Mean absolute deviation}

We also used Mean Absolute Deviation (MAD) as a criterion to compare the ORR methods. MAD is a practical measure because it indicates how close the jobs are completed near their due dates (i.e., just in time philosophy). It is also frequently used in the ORR literature. In our study, MAD provided useful information about the release methods.

First of all, the ANOVA tests showed that all the main factors and their two way interactions are significant. In general, differences between ORR methods become more significant as the load level increases at loose due dates. We also observed that the performance of ORR methods worsened when SPT was used. This rule also increased the differences between the ORR methods

According to the Bonferroni procedure, $\mathrm{PBB}$ is the best ORR method when the system load is high. However, when the load is low CINF yields the best performance. In contrast to the mean flow time criterion, the periodic rules (i.e., PBB, PAGG, IR) start perform better than their continuous counterparts in the MAD case. This shows the advantages of the periodic ORR methods over the continuous rules when the criterion is to complete the jobs on time.

\subsubsection{Other performance measures}

The following observations are made for the other performance measures. First, we noted that the results for mean number of jobs, mean time in the shop, and mean time in system measures are similar to those for the mean flow time criterion. Again, WIBL and CAGG are the two best ORR methods and PINF is the worst. Among the periodic methods, PAGG and PBB improved the system performance more than others. The performance of WIBL and CAGG were also superior for the percent tardy measure. We also noted that IMR can become a competitive policy at the low system utilization level.

For the standard deviation of flow time measure, IMR, CAGG and WIBL performed better than the other release methods at low utilization. In the high utilization case, however, CAGG yielded smaller standard deviation values. Among the periodic release methods, PBB and PAGG stood out as the best. In terms of standard deviation of number of jobs in the shop measure, CAGG was ranked first which was followed by WIBL and other methods. CINF showed the worst performance for this measure due to its lack of ability to control the load level in the shop.

\section{Concluding remarks and suggestions for further research}

In this paper, we have presented a new classification framework for the literature and studied several issues concerning the ORR problem. Specifically, we investigated the research paradox and compared the ORR methods under various experimental conditions for different performance measures. Our major findings are as follows:

1. Overall time in system can be reduced (or the potential benefits of ORR can be realized in simulation models) if congestion on the shop floors is properly modeled. The results also indicated that the due date performances (i.e., tardiness and mean absolute deviation) of the system can be improved considerably by an effective ORR mechanism. In this study, we did not consider the issues such as the difficulty in expediting (and dispatching) due to congestion and the possibility of changes in customer orders or specifications. These real life features, if added to the model, could have further strengthened our conclusion about the benefits of ORR in practice. 
2. We also compared ORR methods under various experimental conditions for different performance measures. To our knowledge, this is the first detailed simulation study in which both periodic and continuous ORR methods are compared simultaneously. The results indicated that continuous rules (i.e., CAGG and WIBL) performed well for the flow time and tardiness related criteria whereas periodic rules such as $\mathrm{PBB}$ and $\mathrm{PAGG}$ showed better performance for the mean absolute deviation criterion. In practice, this means more frequent revisions of ORR decisions (or small period lengths in the periodic release systems) is needed to minimize manufacturing lead times or mean tardiness. For the MAD criterion, it seems that a periodic release mechanism with an appropriate period length can produce satisfactory results.

3. Except for MAD, we did not observe any significant interaction between ORR and dispatching. In the MAD case, however, the performance of ORR methods can be improved more by using due date based dispatching rules (i.e., MOD). The results also indicated that differences in the relative performance of ORR mechanisms become more significant at high utilization rates and with tight due-dates. This means that the ORR function is more important today in highly dynamic and competitive environments where manufacturers have to operate with very tight due-dates and utilize expensive equipment effectively.

In addition, we observed that the current system load and the job due-date information is very important for the successful implementation of the ORR policies. This point should be considered in newly proposed ORR methods. As a future research, there is definitely a need to test the ORR methods under different systems so that the practitioners can select the right models for their different production environments. It would be also interesting to measure the robustness of all these release methods to variations in the system parameters such as changes in due-dates and cancelations of orders so that practitioners can utilize these techniques with a certain confidence.

\section{References}

[1] J. Hutchison, Current issues concerning with FMS scheduling OMEGA 29 (12) (1991) 529-537.

[2] L. Onur, W.J. Fabrycky, An input/output control system for the dynamic job shop, IIE Transactions 19 (1) (1987) 88-96.

[3] O.W. Wight, Input/output control: a real handle on lead times, Production and Inventory Management 11 (1970) 9-30.

[4] K.R. Baker, The effects of input control in a simple scheduling model, Journal of Operations Management 4 (1984) 99-112.

[5] R. Uzsoy, C. Lee, L.A. Martin-Vega, A review of production planning and scheduling models in the semiconductor industry Part II: Shop floor control, IIE Transaction 26 (5) (1994) 44-55.

[6] P.M. Bobrowski, P.S. Park, Work release strategies in a dual resource constrained job shop, Omega 17 (2) (1989) 177-188.

[7] G.L. Ragatz, V.A. Mabert, An evaluation of order release mechanisms in a job-shop environment, Decision Seciences 19 (1) (1988) 167-189.

[8] T.D. Fry, Controlling input: The real key to shorter lead times, The International Journal of Logistic Management 1 (1) (1990) 7-12.

[9] S.A. Melnyk, G.L. Ragatz, L. Fredendall, Load smoothing by the planning and order review/release systems: A simulation experiment, Journal of Operations Management 10 (4) (1991) 512-523.

[10] W. Bechte, Load-oriented manufacturing control, just-intime production for job shops, Production Planning and Control 5 (3) (1994) 292-307.

[11] J.R. Ashby, R. Uzsoy, Scheduling and order release in a single-stage production system, Journal of manufacturing Systems 14 (4) (1995) 290-306.

[12] S.A. Melnyk, K.C. Tan, D.R. Denzler, L. Fredendall, Evaluating variance control, order review/release and dispatching: A regression analysis, International Journal of Production Research 32 (5) (1994) 1045-1061.

[13] F. Mahmoodi, K.J. Doley, P.J. Starr, An evaluation of order releasing and due date assignment heuristics in a cellular manufacturing systems, Journal of Operations Management 29 (4) (1991).

[14] P.R. Philipoom, M.K. Malhotra, J.B. Jensen, An evaluation of capacity sensitive order review and release procedures in job shops, Decision Sciences 24 (6) (1993) 1109-1133.

[15] T.E. Vollmann, W.L. Berry, D.C. Whybark, Manufacturing Planning and Control Systems, 2nd ed., Irwin, Illinois, 1988.

[16] S.A. Melnyk, G.L. Ragatz, Order review/release issues and perspectives, International Journal of Production Research 27 (7) (1989) 1081-1096.

[17] S.S. Panwalkar, M.L. Smith, R.A. Dudek, Scheduling with periodic release of orders for production, Presented at ORSA/TIMS Special Interest Conference on the Theory and Application of Scheduling, 1976. 
[18] L.C. Hendry, S.K. Wong, Alternative order release mechanisms: A comparison by simulation, International Journal of Production Research 32 (12) (1994) 2827-2842.

[19] S.J. Kim, P.M. Bobrowski, Evaluating order release mechanisms in a job shop with sequence-dependent set-up, Production and Operations Management 4 (2) (1995) 163-180.

[20] I. Ahmed, W.W. Fisher, Due date asingment, job order release, and sequencing interaction in job shop scheduling, Decision Sciences 23 (3) (1992) 633-646.

[21] K.-W. Hansmann, Capacity oriented production control for a job shop production, Operations Research in Production Planning and Control. Proceedings of a Joint German/US Conference, Springer Berlin, 1993, pp. 89-105.

[22] L.M. Roderick, D.T. Phillips, G. Hogg, CONWIP: A pull alternative to Kanban, International Journal of Production Research 28 (5) (1990) 879-894.

[23] C.R. Glassey, M.G.C. Resende, Closed-loop job release control for VLSI circut manufacturing, IEEE Transactions on Semiconductor Manufacturing 1 (1) (1988) 36-46.

[24] M.L. Spearman, Woodruff, W. Hopp, A comparison of orde release strategies in production control systems, International Journal of Production Research 30 (3) (1992) 611-626.

[25] L.C. Hendry, B.G. Kingsman, Job release: Part of a hierarchical system to manage manufacturing lead times in make-to-order companies, Journal of Operational Research Society 42 (10) (1991) 61-70.

[26] J.C. Irastorza, R.H. Deane, A loading and balancing methodology for job shop control, AIIE Transactions 6 (4) (1974) 300-307.

[27] E. Goldratt, R.E. Fox, The Race, North River Press, New York, 1986.

[28] P.S. Park, P.M. Bobrowski, Job Release and labour flexility in a dual resource constrained job shop, Journal of Operations Management 8 (3) (1989) 230-249.
[29] P.M. Bobrowski, Implementing a loading heuristic in a discrete release job shop, International Journal of Production Research 27 (11) (1989) 1935-1948.

[30] S. Lingayat, J. Mittenthal, R.M. O'Keefe, An order release mechanism for a flexible flow line, International Journal of Production Research 33 (5) (1995) 1241-1256.

[31] H.-P. Wiendahl, J. Glässner, D. Petermann, Application of load-oriented manufacturing control in industry, Production Planning and Control 3 (2) (1992) 118-129.

[32] W. Bechte, Theory and practice of load-oriented manufacturing control, International Journal of Production Research 26 (3) (1988) 375-395.

[33] S.A. Melnyk, D. Denzler, G.L. Magnan, L. Fredendall, An experimental model for investigating the sensitivity of job shop performance to job rlease time distribution parameters, Production and Operations Management 3 (1) (1995) 64-74.

[34] M.K. Malhotra, J.B. Jensen, Dooley, P.R. Philipoom, Management of vital customer priorities in job shop manufacturing environments, Decision Sciences $25(5 / 6)$ (1995) 711-736.

[35] C.D. Pegden, R.E. Shannon, R.P. Sadowski, Introduction to Simulation Using SIMAN, McGraw-Hill, Englewood Cliffs, NJ, 1990.

[36] P.J. Egbelu, M.A. Tanchoco, Characterization of automatic guided vehicle dispatching rules, International Journal of Production Research 22 (3) (1983) 359-375.

[37] K.R. Baker, Sequencing rules and due-date assignments in a job shop, Management Science 30 (1984) 1093-1104.

[38] A. Sabuncuoğlu, A study of schudling rules of FMSs: A simulation approach, International Journal of Production Research 36 (2) (1998) 527-546.

[39] A.M. Law, W.D. Kelton, Simulation Modeling and Analysis, 2nd ed., McGraw-Hill, Singapore, 1991. 